\title{
Effect of thermal residual stresses on bonded structures containing cold expanded and bolted holes
}

\author{
Abdul Khadar Syed ${ }^{1} \mathrm{a}^{*}$, Michael E Fitzpatrick $^{2 \mathrm{~b}}$, James E Moffatt ${ }^{3 \mathrm{c}}$ \\ 1, 2, 3 Materials Engineering, The Open University, Walton Hall, Milton Keynes MK7 6AA, UK

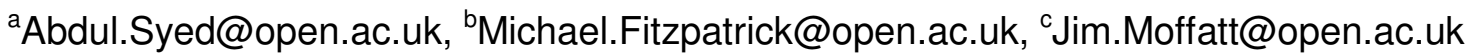

Keywords: Cold expansion, Fastener holes, GLARE, Residual stress

\begin{abstract}
The primary focus of this investigation is to determine the distribution of thermal residual stresses that result during composite bonding processes, and the effect on stresses generated during the subsequent cold expansion of holes. Residual stress measurements were carried out using neutron diffraction techniques. Results show that the cold expansion process resulted in radial compressive stresses 3-4 $\mathrm{mm}$ from the edge of the hole and there was no significant effect of thermal residual stresses from the bonding process on the cold expansion and bolted stresses.
\end{abstract}

\section{Introduction}

Structural joints which incorporate bolts and rivets are extensively used in aircraft structures and fatigue failure is an important consideration. These structural joints become the most sensitive locations and are considered as fatigue critical locations. In aircraft during service these structural joints are vulnerable to fatigue loading which may result in the initiation of fatigue cracks, propagation and eventual structural failure. Crack propagation will take the least resistant path within the structure. There are two traditional types of manufacturing processes for aircraft structures: integrally machined and mechanically fastened. Integrally machined processes produces a high scrap rate of expensive aluminium alloys which results in a high manufacturing cost. Structures produced by mechanical fastening have to rely on numerous riveted and bolted joints which are potential failure locations due to a higher stress concentration factor associated with fastener holes [1]. In order to improve the damage tolerance and avoid large penalising safety factors, selective reinforcement such as novel crack retarding features can be incorporated into critical locations within the structure.

In recent years much attention has been focused in increasing the fatigue performance of aircraft integral structures. One promising solution is to incorporate adhesively bonded composite patches as reinforcements in critical structural locations. These have been proven to be effective in enhancing the fatigue performance of the structure by retarding crack growth $[2,3]$. The principle is to adhesively bond a stiffening strap in critical locations and the resultant local increase in stiffness will bridge a growing crack and reduce the crack driving force. Bonded composite patches not only improve the fatigue performance of the structure but also result in weight savings compared to riveted and bolted reinforcements.

Glass Laminate Aluminium Reinforced Epoxy (GLARE) fibre metal laminate is the most promising material as stiffening straps which consist of alternative layers of aluminium (0.2 to 0.5 $\mathrm{mm}$ thick) and glass fibre impregnated epoxy layers [4]. GLARE posses high damage tolerance, with good fatigue resistance and high overall mechanical properties [5, 6]. However one common problem arises as a result of difference in coefficients of thermal expansion between the strap and the metallic substrate. Since the curing process of strap bonding to the substrate takes place at high temperature, thermal residual stresses can arise, owing to the mismatch in thermal expansion coefficient between the strap and substrate, which may cause adverse effects on the mechanical performance of the structure [7, 8]. Thermal residual stresses in the substrate for a GLARE/aluminium combination are tensile in nature and may create a higher mean stress intensity factor at the crack tip and as a consequence a reduction in structural durability. A common approach 
for minimizing thermal residual stresses is by reducing the curing temperature and increasing the curing time. This leads to high production costs and may lead to the reduction of structural integrity [9].

In practice a reinforcing strap will require additional fixing by means of bolting to increase the fail safety and these holes will be cold worked to generate beneficial radial compressive stresses and to enhance the fatigue performance. Cold expansion can be achieved by different procedures. A common process is to insert an oversized tool from one side of a holed plate and extract it from the opposite side [10, 11]. In this paper the split-sleeve cold expansion process was used for cold expansion and was carried out after bonding the strap onto the metal substrate. Thermal residual stresses may interact and have significant effect on the beneficial cold expansion stresses. Hence it is very important to investigate the thermal residual stresses developed during strap bonding process to ensure the damage tolerance of the structure.

\section{Experimental materials and methods}

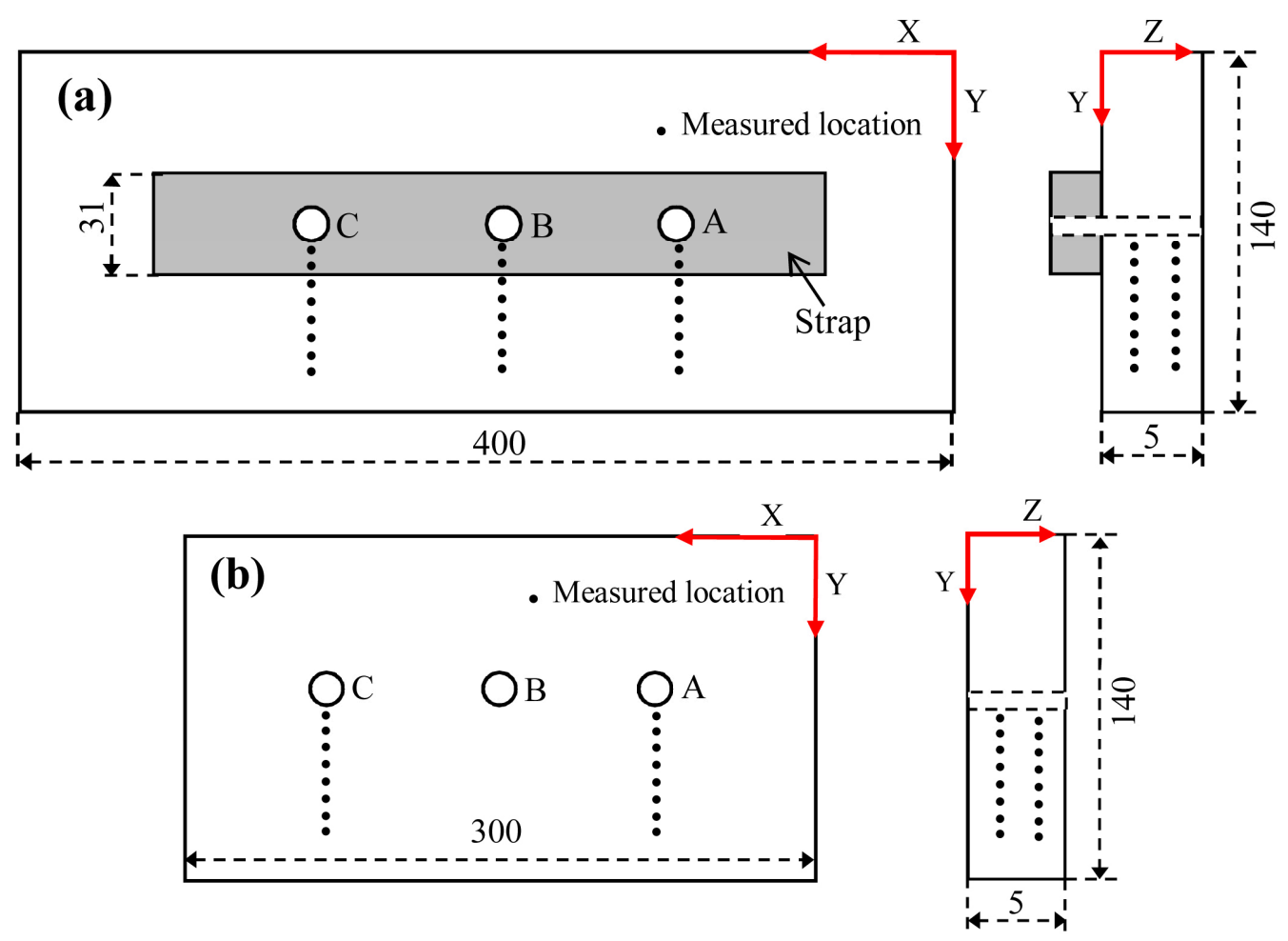

All dimensions are in mm, A-Cold expanded hole, B-Drilled hole and C-Bolted hole

Fig.1. Geometrical details of specimens (a) with and (b) without reinforcing strap.

A total of two specimens were prepared, one without a reinforcement strap and the second with a reinforcement strap. Both the specimens were extracted from a 5-mm-thick plate of aluminium alloy 2624-T351. Table 1 shows the mechanical properties of the materials used in this investigation. For the reinforced specimen, GLARE 2(6/5), $3.7 \mathrm{~mm}$ thick, was used as a strap, which consists of alternate layers of 6 aluminium sheets and 5 double layers of unidirectional glass fibres reinforced in FM94 epoxy adhesive designated as FM94/S2 prepreg. FM 94® a high temperature cure adhesive supplied by Cytec Ltd [12], was used to bond the strap on to the substrate. The curing temperature of the adhesive is $120^{\circ} \mathrm{C}$. Both the specimens contains a cold expanded hole $(\mathrm{CE})$, a drilled hole $(\mathrm{DH})$ and a bolted hole $(\mathrm{BH})$ represented by $\mathrm{A}, \mathrm{B}$ and $\mathrm{C}$ respectively as shown in Fig1. The bolted hole was cold expanded prior to installing the bolt. Both the specimens were $2 \%$ cold worked by using a split sleeve mandrel of $5.66 \mathrm{~mm}$ nominal diameter and the final diameter of all the holes was $6.27 \mathrm{~mm}$. 
Table.1. Mechanical properties of materials used in this investigation.

\begin{tabular}{|c|c|c|c|}
\hline \multirow{2}{*}{} & \multirow{2}{*}{ Al 2624-T351 } & \multicolumn{2}{|c|}{ GLARE constitutes } \\
\cline { 3 - 4 } & & Al 2024-T3 & FM94/S2-prepreg \\
\hline$E_{l} / \mathrm{GPa}^{1}$ & 73 & 72 & 50.3 \\
$E_{2}, E_{3} / \mathrm{GPa}$ & 71 & 72 & 5.5 \\
$v_{12}=v_{13}$ & 0.33 & 0.30 & 0.310 \\
$v_{21}$ & 0.33 & 0.30 & 0.034 \\
$\alpha_{1} /{ }^{\circ} \mathrm{C}^{-1}$ & $2.32 \times 10^{-5}$ & $2.32 \times 10^{-5}$ & $2.88 \times 10^{-6}$ \\
$\alpha_{2} /{ }^{\circ} \mathrm{C}^{-1}$ & $2.32 \times 10^{-5}$ & $2.32 \times 10^{-5}$ & $4.03 \times 10^{-5}$ \\
Density $/ \mathrm{kg}^{-5} \mathrm{~m}^{-3}$ & 2770 & 2770 & 1972 \\
\hline
\end{tabular}

${ }^{1}$ Young's modulus used in computation of residual stress

Residual stress measurements were performed using neutron diffraction. Neutron diffraction is an established non-destructive technique used to determine the strains within metallic structures [13]. Residual stress measurements were performed at SALSA, ILL and ENGIN-X, ISIS. SALSA is a monochromatic strain diffractometer [14] where single lattice reflections are measured. Aluminium is face centred cubic and measurements were made using the $\{311\}$ lattice plane as this has been found to give the best approximation to the macroscopic strain response. The wavelength used was $1.648 \AA$. ENGIN-X is a time-of-flight (TOF) neutron diffractometer based at the ISIS pulsed neutron source [15] where multiple reflections were measured and a Pawley or Rietveld refinement was used to determine the lattice spacing in the measured direction. For both the measurements, a gauge volume of $2 \times 2 \times 2 \mathrm{~mm}^{3}$ was used. Stress free reference measurements were performed in three principle directions by using a $3 \times 3 \times 3 \mathrm{~mm}^{3}$ cube extracted from the edge of the measured plate.

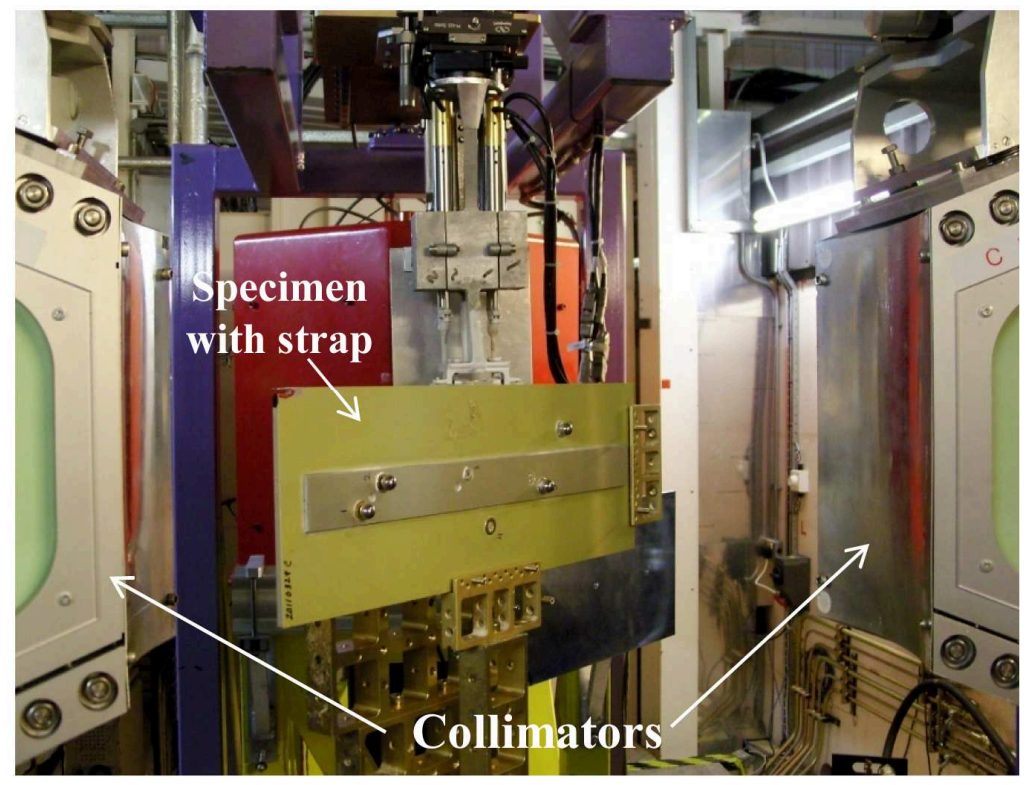

Fig.2. Experimental setup at ENGIN-X, ISIS

Fig 2 shows the experimental setup at ENGIN-X. All the residual stress measurements were performed in the substrate in three principal directions inferred from the geometry and symmetry around the holes, starting from the edge of the hole and progressing towards the edge of the specimen in the y-direction (see Fig 1). Measurements were performed on all three holes on the specimen with a strap and at the $\mathrm{CE}$ and $\mathrm{BH}$ holes on the specimen without strap. Measurements were not carried out at DH on the specimen without strap as there will be no residual stresses present as the hole was not cold worked. All the measurements were performed in two different thickness locations, $\mathrm{z}=1.5$ and $3.5 \mathrm{~mm}$ from the reinforced side; though owing to time constrains measurements were performed only at $\mathrm{z}=1.5 \mathrm{~mm}$ at the $\mathrm{BH}$ in both specimens. 


\section{Results and discussion}

The data obtained were analysed in depth and for brevity only the hoop stresses are presented here as they are the most important in the cold expansion process. Fig 3 shows the evolution of the residual stresses for $\mathrm{CE}$ and $\mathrm{DH}$ with strap and $\mathrm{CE}$ without strap at $\mathrm{z}=1.5 \mathrm{~mm}$. From fig 3 it can be observed that tensile thermal residual stresses are induced in the substrate under the strap, which range from 20-50 $\mathrm{MPa}$, owing to the high temperature adhesive curing. The cold expansion process resulted in radial compressive stresses around the hole up to $3-5 \mathrm{~mm}$ from the edge of the hole in both specimens. Measurements performed at CE on the specimen with strap shows no significant variation in the peak compressive stresses at the edge of the hole compared to the specimen without a strap. As the measurements progressed towards the edge of the specimen (in y-direction), compressive stresses diminished and stresses become approximately zero in the specimen without strap whereas small tensile stresses can be observed in the specimen with strap.

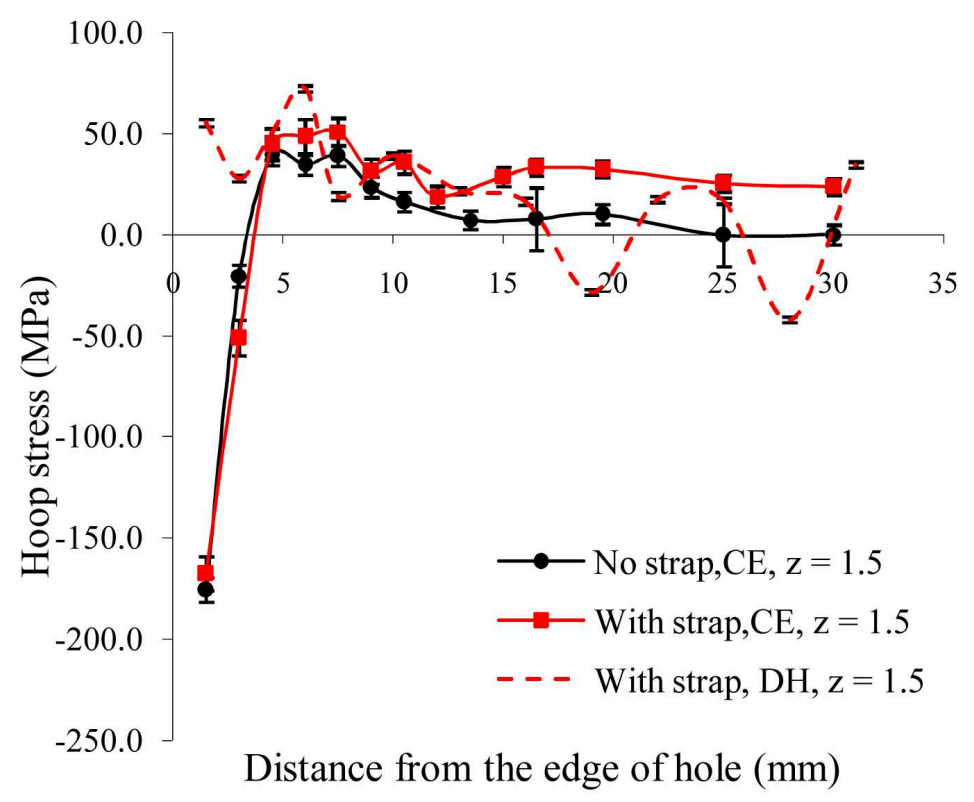

Fig.3. Hoop stresses of specimen with and without reinforcing strap at $\mathrm{CE}$ and $\mathrm{DH}$, at $\mathrm{z}=1.5$

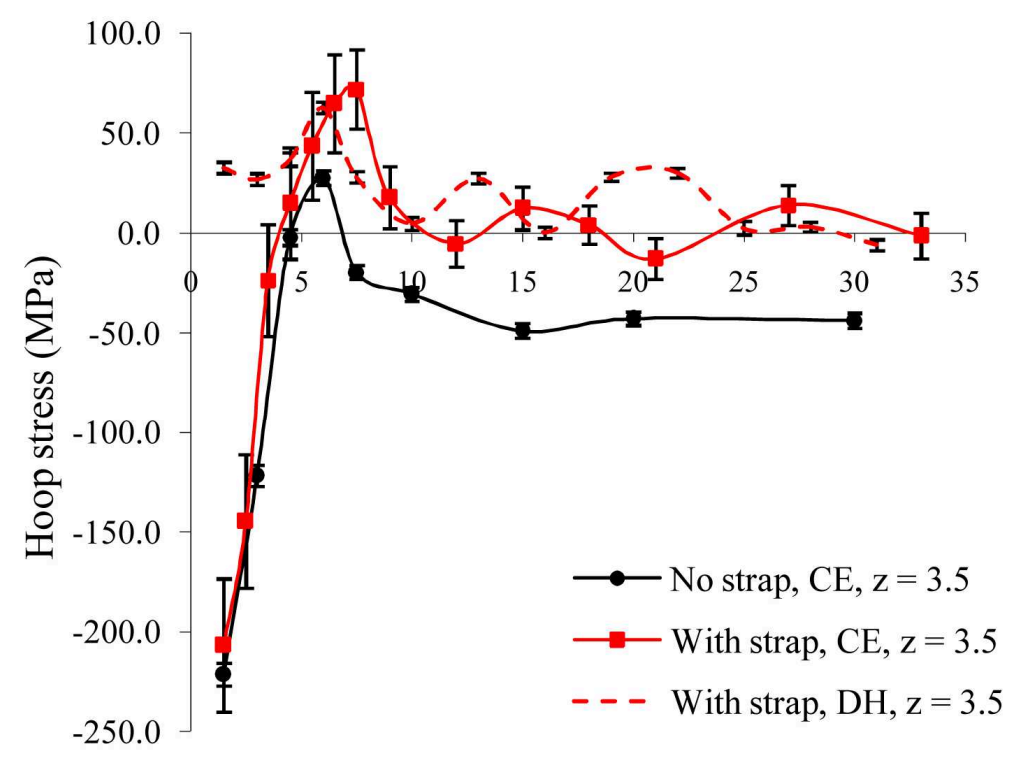

Distance from the edge of hole $(\mathrm{mm})$

Fig.4. Hoop stresses of specimen with and without reinforcing strap at $\mathrm{CE}$ and $\mathrm{DH}$, at $\mathrm{z}=3.5$ 
Measurements performed at $\mathrm{z}=3.5$ on specimen with a strap at $\mathrm{CE}$ and $\mathrm{DH}$ and specimen without strap at $\mathrm{CE}$ are shown in fig 4. Measurements at DH shows tensile stresses under the strap resulted due to strap bonding process and ranging from 20-50 MPa. Measurements at $\mathrm{CE}$ on both the specimens shows radial compressive stresses near the edge of the hole resulted from cold expansion process and there is no significant variation in the peak compressive stresses between the specimen with and without strap. As the measurements progressed in y-direction the compressive stresses are seen to diminish. Specimen with strap, $\mathrm{CE} \mathrm{z}=3.5$ shows higher tensile stresses at $5-10 \mathrm{~mm}$ from the edge of the hole compared to the specimen without strap, which may be attributed to the thermal residual stresses generated during the strap bonding process. Furthermore, as expected, due to the cold expansion process where the mandrel pushes material from the inlet face $(\mathrm{z}=1.5)$ to the outlet face $(z=3.5)$ there is higher total deformation at the outlet face hence higher compressive stresses can be observed than at the inlet face.

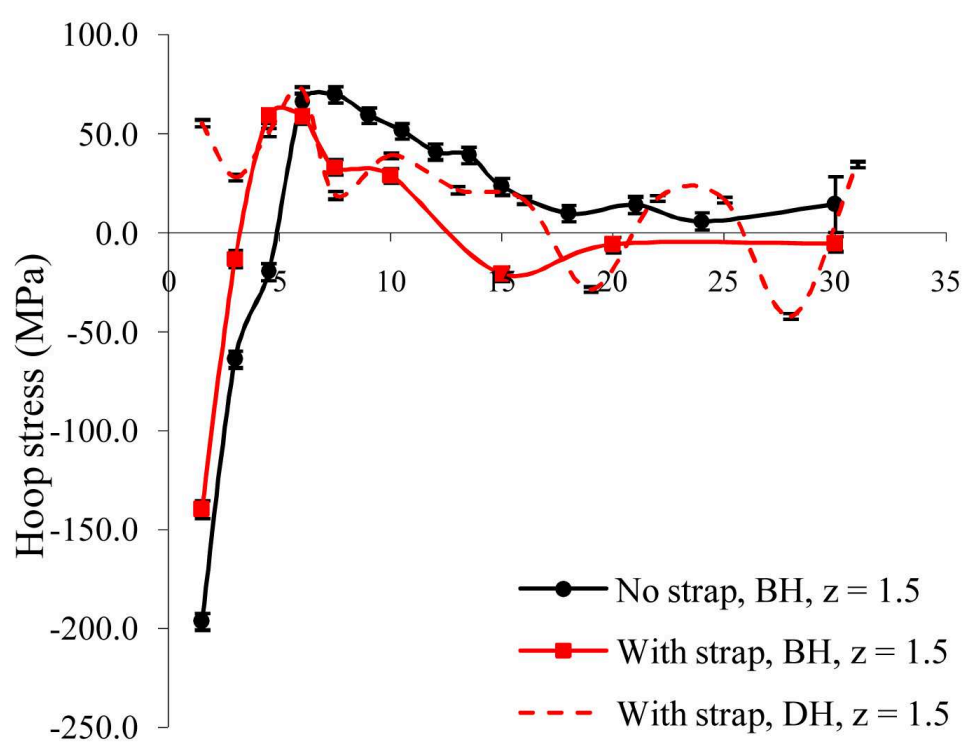

Distance from the edge of hole $(\mathrm{mm})$

Fig.5. Hoop stresses of specimen with and without reinforcing strap at $\mathrm{BH}$ and $\mathrm{DH}$, at $\mathrm{z}=1.5$

Fig 5 shows residual stress measurements at bolted hole $(\mathrm{BH}), \mathrm{z}=1.5 \mathrm{~mm}$. Before installing the fastener, the holes were cold expanded. Radial compressive stresses resulting from the cold expansion can be observed around the hole up to $5 \mathrm{~mm}$ from the edge of the hole. Peak compressive stress at the edge of the hole is higher for the specimen without strap. This might be attributed to the effect of additional compressive stresses developed during the fastener installation whereas there was no effect of fastener stresses observed on the specimen with a strap. As the measurements progressed towards the edge of the specimen compressive stresses are seen to diminish and balancing tensile stresses were observed.

\section{Conclusions}

1. The residual stresses associated with the strap bonding process and their effect on cold expansion stresses and bolting stresses have been studied using neutron diffraction.

2. The strap bonding process resulted in the development of thermal residual stresses in the substrate, which are very low, as a consequence of the mismatch in coefficient of thermal expansion between the GLARE and the aluminium.

3. Cold expansion resulted in the development of radial compressive residual stresses around the hole that were higher at the outlet face and lower at the inlet face.

4. Thermal residual stresses have no significant effect on the cold expansion stresses and bolted stresses. 


\section{Acknowledgements}

This research is supported by the UK Technology Strategy Board via the AIRSTREAM programme, in collaboration with Airbus, Alcoa and Cranfield University. MEF is grateful for funding from the Lloyd's Register Foundation (LRF), a UK registered charity and sole shareholder of Lloyd's Register Group Ltd, that invests in science, engineering and technology for public benefit, worldwide.

\section{References:}

[1]. Xiang Zhang and Yazhi Li, Damage tolerance and fail safety of welded Aircraft wing panels, AIAA journal, 43, 7, (2005), pp. 1613-1623.

[2]. A. A. Baker, Repair of Cracked or Defective Metallic Aircraft Components with Advanced Fibre Composite-an Overview of Australian Work, Composite Structures 2, (1984), pp.153-181.

[3]. A. A. Baker, Bonded composite repair of fatigue-cracked primary aircraft structure, Composite Structures 47 (1999), pp. 431-443.

[4]. A. Vlot, Glare, history of the development of new aircraft material, Kluwer academic publishers, (2001).

[5]. Wu Guocai and J.M. Yang, The mechanical behavior of GLARE laminates for aircraft structures, JOM, 57, 1, (2005), pp. 72-79.

[6]. F. Bagnoli, M. Bernabei, D. Figueroa-Gordon, P.E. Irving, The response of aluminium/GLARE hybrid materials to impact and to in-plane fatigue, Material science \&engineering A, 523, 1-2, (2009), pp. 118-124.

[7]. D. R. Daverschot, A. Vlot and H. J. M. Woerden, Thermal Residual Stresses in Bonded Repairs, Applied Composite Materials 9 (2002), pp. 179-197.

[8]. C.D.M. Liljedahl, M.E. Fitzpatrick and L. Edwards, Residual stresses in structures reinforced with adhesively bonded straps designed to retard fatigue crack growth, Composite Structures 86 (2008), pp. 344-355.

[9]. C.L. Ong, and S. Shen, The reinforcing effect of composite patch repairs on metallic aircraft structures, International Journal of Adhesion and Adhesives 12 (1992), pp. 19-26.

[10]. Y. Zhang, M. E. Fitzpatrick and L. Edwards, Analysis of the Residual Stress around a Coldexpanded Fastener Hole in a Finite Plate, Strain 41 (2005), pp. 59-70.

[11]. J. Liu, X.J. Shao, Y.S. Liu, Z.F. Yue, Effect of cold expansion on fatigue performance of open holes, Materials Science and Engineering A 477 (2008), pp. 271-276.

[12]. http://www.cemselectorguide.com/pdf/FM_94_032910.pdf, Accessed 14 December, 2013.

[13]. M.E. Fitzpatrick and A. Lodini, Analysis of Residual Stress by Diffraction using Neutron and Synchrotron Radiation, Taylor \& Francis, (2003).

[14]. Thilo Pirling, Giovanni Bruno, and Philip J. Withers, SALSA-A new instrument for strain imaging in engineering materials and components, Materials Science and Engineering A 437, (2006), pp. 139-144.

[15]. J.R. Santisteban, M.R. Daymond, J.A. James and L. Edwards, ENGIN-X: a third-generation neutron strain scanner, Journal of Applied Crystallography, 39, (2006), pp. 812-825. 